\title{
Hitos provisionales en el perfil de una generación: poetas mexicanos nacidos entre 1975 y $1985^{1}$
}

\author{
Alejandro Higashi \\ Universidad Autónoma Metropolitana - Iztapalapa \\ higa@xanum.uam.mx
}

\begin{abstract}
RESUMEN: En este artículo exploro aspectos característicos de la generación nacida entre 1975-1985 (una ausencia de movimientos sociales suficientemente importantes como para vincularlos; nuevas formas de relación institucional en un proceso de profesionalización poética; la consecución de una poesía de ruptura, pero ahora en copresencia y no en estratos generacionales), con el propósito de explicar la dispersión estética y temática que termina por identificar su obra.
\end{abstract}

AвSTRACT: In this article, I explore some features of the poetic generation born between 1975-1985 (the lack of relevant social movements that integrates them as a group; new forms of institutional relationship in a process of poetic professionalization; a tradición de la ruptura poetry made it in copresence and not in a generational strata rupture) with the purpose of explaining the thematic and aesthetic dispersion that identifies their work.

Palabras Clave: Poesía mexicana 1975-1985, poesía y apoyo del Estado, poesía y profesionalización, poesía de ruptura en copresencia, poesía y crematística. KeYwords: Mexican Poetry (1975-1985), Poetry and State support, Poetry and professionalization, Poetry de ruptura in copresence, Poetry and chrematistic.

\section{UNA IDENTIDAD PROVISIONAL PARA LA POESÍA MEXICANA MÁS RECIENTE}

No voy a entrar en la discusión teórica sobre el concepto de "generación” por una buena razón: otros lo han hecho muy bien y con exce-

${ }^{1}$ Las observaciones aquí presentadas se benefician del trabajo cotidiano al interior del Seminario de Investigación en Poesía Mexicana Contemporánea <http://www.seminariodepoesiamexicana.org/>, conformado por Jorge Aguilera López, Eva Castañeda Barrera, Roberto Cruz Arzabal, Manuel Iris, Jocelyn Martínez Elizalde, Mariana Ortiz Maciel, Alejandro Palma, Israel Ramírez y Cristina Rivera Garza, en funciones desde el 2010 y al que me integré al inicio del 2012. Agradezco a los miembros de dicho Seminario mucha de la información aquí vertida, pero asumo la responsabilidad por las opiniones expuestas. 
lentes resultados; hoy podemos acercanos al problema desde una perspectiva eminentemente teórica, como la de Eduardo Mateo Gambarte, o desde ingeniosas propuestas prácticas como la iniciativa de Gabriel Zaid en su Asamblea de poetas jóvenes de Mexico (1980), donde ya se advierten muchos de los problemas que se intentarían solucionar después, hasta llegar a los esfuerzos multiplicados en ejercicios críticos bien calculados, en ocasiones atrevidos, como los de Evodio Escalante (1985), Gustavo Jiménez Aguire, Ernesto Lumbreras y Hernán Bravo Varela, Rodolfo Mata (2004 y 2006), Samuel Gordon (129-133), Julián Herbert (2010: 20-23), Malva Flores (81-195) o Maricela Guerrero (8394) (aunque es bien cierto que, en muchos de los casos, se refieren a promociones anteriores a la que trato aquí). El camino del empirismo ofrece resultados probados; por el contrario, la definición teórica de una generación fracasa por su enorme grado de generalización (y por escepticismo y hasta rechazo de los propios miembros; por ejemplo, Maricela Guerrero: 83-85).

Encontrar los perfiles de una generación, por supuesto, no resulta sencillo: al estar constituida por poetas que publican su primer libro durante la década del 2000, nacidos en su mayoría alrededor de 19751985, representan la siguiente generación al grupo que ya Samuel Gordon había identificado en 2004 por su trabajo individual, su dispersión geográfica, su variedad de estéticas, su pluralidad ideológica y, en suma, por una "similitud de lo disimilar" (Gordon: 138-140). Por otro lado, sería de esperar que el fenómeno de sobrepoblación poética que advertía Gabriel Zaid en la Asamblea de poetas jóvenes de México (1980: 12 y Lumbreras y Bravo Varela: 18-19) se haya agudizado y que el panorama de dispersión esbozado por Gustavo Jiménez Aguirre solo se haya vuelto más abigarrado, ante la falta de una voz hegemónica expresada en los formatos de una antología poética o una revista influyente, situación que comparten con los poetas de generaciones previas (74-75).

Resulta difícil un censo de poetas (aunque la Coordinación Nacional de Literatura del INBA o de Conaculta probablemente cuente con las herramientas para hacerlo) y volver a trillar sobre un concepto ingenioso como el de asamblea de poetas pergeñado por Zaid en 1980 parece imposible ante el número de publicaciones. Crear un canon a partir de muchos primeros libros de poemas tampoco resuelve las cosas; no hay que olvidar que el canon es la mejor herramienta para NO leer. Un canon señala los libros que debemos leer, pero rápidamente nos distrae de 
todo lo demás. Esto, sin perder de vista que en México el canon poético se origina en los mismos poetas y solo después es respaldado por la crítica (Stanton 2001: 53). Un ejercicio posible sería el de leer un corpus de las antologías de poesía mexicana actual, aunque en la práctica resulta irrealizable por la multiplicación de antologías (Julián Herbert se refiere a las "multitudinarias, ilegibles antologías que aparecen con regularidad casi hemerográfica" para documentar la presencia de los nuevos poetas; 2010: 20), por las suspicacias que despierta la disparidad de criterios de selección, a menudo extrapoéticos, y por las semejanzas entre ellas (Fernández Granados se refiere a un "laboratorio clónico"; 2008). Una crítica seria e informada, que reseñara los libros como aparecen, sería una solución; en México, por desgracia, el periodismo cultural resulta ineficaz ante el "ahi se va" de editores mal formados y mal informados (Zaid 2013: 59-65); en el terreno de la crítica literaria, la situación no mejora: como apunta Mario Bojórquez, el ejercicio crítico "ha sido hasta ahora sobrellevado por los propios autores" (213), lo que implica un conflicto de intereses, agravado por la existencia de un entorno mercantil (Volpi: 24-28). La crítica académica, por otro lado, despierta desconfianza en algunos sectores por su conservadurismo (por ejemplo, Julián Herbert 2010: 58-59).

Sin embargo, hay que empezar por algún lado. Como efecto de la sobrepoblación poética, la convivencia entre creadores parece centrarse en una competencia por la búsqueda de valores simbólicos que los identifiquen (como el grado de originalidad del proyecto personal o el número de actividades en su currículum) y no por la colaboración (lo que explica que falten manifiestos comunes y proyectos de grupo). Por esta razón, resulta difícil encontrar similitudes en la estética de los miembros de la misma generación, preocupados por crear una obra disimilar. Muchos de ellos, por otra parte, se encuentran al inicio de su carrera (algunos apenas han publicado su primer libro), lo que difícilmente permite llegar a conclusiones definitivas. Los títulos que aparecen a lo largo del presente trabajo no representan una lista de lo publicado en 2000-2010 ni mucho menos; tampoco es un listado de lo "mejor" o de aquello que perdurará durante los siguientes ańos; por encima de todo, no representan un canon. Me refiero, simplemente, a libros que circulan, que se reseñan y que, en muchos casos, he leído por conocer directamente a los autores (a causa de la pobre comercialización de la poesía en México, los libros se publican, pero rara vez se distribuyen). Se trata 
de una muestra sucinta, de un florilegio, de los andamios para empezar la obra con un corpus provisional que nos permita ver algunas de las tendencias de este grupo amplio, disimilar, autogenerativo, dinámico y rizomático, sin apabullarnos por el volumen de lo publicado y por las notables diferencias entre los textos. Por otro lado, en este trabajo no me concentro en identificar tendencias estéticas (estructurales, formales), esfuerzo que sin duda requeriría de un corpus cerrado para ofrecer conclusiones de algún valor. Ante un conjunto caracterizado por su heterogeneidad, prefiero una vía más productiva de reflexión: la identificación de los fenómenos sociales que conducen a la dispersión estética en estos autores jóvenes y que nos permiten agruparlos como una generación (desde la perspectiva orteguiana), aunque su obra muestra la capacidad de todos estos autores para hacer de las diferencias estéticas una suerte de poética o propuesta estética. Si el concepto de identidad, basado en características comunes, resulta ajeno a esta poesía desde su propia raíz, quizá la explicación no esté en la inmanencia de una obra estética diversificada, sino en las circunstancias en las que se produce.

\section{LA PROFESIONALIZACIÓN DEL POETA COMO UN PERFIL CREADOR}

La oferta sin precedentes que se ha experimentado en el terreno poético luego de varias iniciativas editoriales públicas y privadas en los años 1980-2010 (por ejemplo, Gabriel Bernal Granados o León Plascencia Nol: 235) ha generado una bonanza editorial donde, para destacar, no basta llegar al santo grial del libro, porque se llega por varias vías. Para los autores que publican su primer libro en la década de 2000-2010, el poeta ya no atrae la atención por ser un "buen poeta" a secas y por tener un buen libro publicado, sino que parece obligado a presentar propuestas originales todo el tiempo que le permitan descollar en un mercado editorial congestionado. ${ }^{2}$

2 Donde la colección de Tierra Adentro ronda ya los 500 números (entre ensayo, cuento, novela y poesía), el catálogo de VersodestierrO llega casi a los cuarenta títulos, la serie de Cuadernos de la Salamandra de Ediciones sin Nombre anda en los 140 títulos y Almadía supera ya la veintena (aunque la gran mayoría de autores en el catálogo de las dos últimas editoriales pertenece a generaciones previas). En el caso de la poesía joven que se escribe en provincia, las imprentas de los Gobiernos locales representan una buena oportunidad para publicar, aunque resulta limitada por su prestigio (fuera de 
En un terreno con esta oferta, las oportunidades deben administrarse. Lo primero que aprendimos como país durante la presidencia de Echeverría fue que el ejercicio de generosos fondos públicos para la cultura (como compensación a la represión de los movimientos del 68 y del 71) traía tras de sí una intensa burocratización (Zaid 2013: 22-30); una intensa burocratización es lo que esta generación ha recibido como herencia después de muchos tanteos. ${ }^{3}$ El poeta-becario, una figura de nuestra modernidad mexicana, pasa de ser un artista marginal a ser un creador en un proceso de profesionalización donde ya no solo necesita ser buen poeta, porque se le piden muchas otras credenciales: libros publicados, publicaciones en revistas prestigiosas y en antologías, premios, entrevistas, congresos para entrar en comunicación con profesionales de otras latitudes, lecturas públicas, trabajo social (en forma de talleres itinerantes), etcétera.

La concepción del poeta como poeta-becario o poeta en proceso de profesionalización no me parece común ni explícita en las discusiones sobre la poesía más reciente; quizá resulte un poco incómoda y de mal gusto, en un espacio de creación subordinado al que, como apunta Rodolfo Mata, es uno de los principales vicios de la poesía mexicana, esa "concepción engolada del lugar del poeta y el valor de la poesía, que tiene que ver con el espíritu solemne tan arraigado en el país" (2006: $\mathrm{s} / \mathrm{p})$. Pese a ello, me parece importante exponer esta circunstancia nodal y discutirla, porque muchos de los rasgos de la producción del periodo

una colección más uniforme, como Tierra Adentro) y capacidad de difusión fuera de los puntos de venta regionales. Muchos de estos libros se publican por una vía doblemente eficiente, la del concurso, donde al ganar un premio se obtiene también el capital simbólico del prestigio del premio y la publicación de la obra. Ello, sin contar las numerosas oportunidades de autopublicación, con resultados muy sobresalientes en algunos casos, como sucede con la colección "Destos deme dos" de la Editorial Start/Pro, con Mónica Gameros e Israel Miranda, así como en otros espacios alternativos mucho más modestos como el blog.

${ }^{3}$ Con la fundación del Consejo Nacional para la Cultura y las Artes en 1988, se creó (no sin esfuerzo y tras varias tentativas) una plataforma organizativa en la que, al menos desde la perspectiva de la poesía, los poetas consagrados por el Sistema Nacional de Creadores de Arte se convertían en administradores intelectuales de la riqueza y los demás poetas, por lo general en un rango de edad menor, en becarios. La fórmula varía (en la Fundación para las Letras Mexicanas, por ejemplo, hay una decidida vocación docente que no hay en el Fondo Editorial Tierra Adentro o en el programa de Jóvenes Creadores del FONCA), pero la escala de evaluación sigue más o menos las mismas pautas de las entidades públicas de evaluación. 
pueden entresacarse de esta forma de escribir poesía (quizá el rasgo sociológico más distintivo con las promociones anteriores). El tema se volvió relevante desde que Rogelio Guedea y Jair Cortés llamaron la atención sobre él en $A$ contraluz: poéticas y reflexiones de la poesía mexicana reciente (especialmente en los textos de Julián Herbert y Mario Bojórquez, centrados no tanto en una "poética personal", sino en un estado de la cuestión sobre la escritura de poesía en México), aunque opino que con sustancial atención a los daños. ${ }^{4}$ Quizá los aspectos más importantes de todo este panorama sean los que interfieren de manera directa con el producto poético; como escribe Rodolfo Mata, cuando "los premios y las becas distorsionan la producción poética, pues fomentan una preparación no para la poesía, sino para aparecer en los periódicos, los festivales, las antologías" (2006: s/p).

Pese al interés y oportunidad de estas reflexiones, no creo que el proceso de institucionalización desemboque siempre en consecuencias negativas ni tampoco que el hablar de un poeta profesional sea un tratamiento humillante que lo rebaja a burócrata de las letras (o, peor aún, al "poeta esclavo de las relaciones culturales" expuesto por Mario Bojórquez: 212): el concepto describe, simple y llanamente, una realidad social cuyas consecuencias resultan relevantes, en última instancia, dentro de la propia creación poética. Si despojamos esta situación de

${ }^{4}$ Para Julián Herbert (2005: 202-205), el fenómeno representa un "trauma generacional" que promueve cierta autocomplacencia entre los creadores (quienes, al final, se disculpan achacando los problemas a las instituciones culturales); Mario Bojórquez (208-215) enfatiza las consecuencias de la burocratización en distintos planos: la homogeneidad de los textos producidos en talleres literarios (poemarios con unidad discursiva, de unas 60 páginas, con tema global), falta de una crítica seria debido al trabajo corporativo (que implica pertenecer a un grupo o no), la burocratización del proceso y la formación de cotos de poder, etc. Otros autores, esporádicamente, han vuelto sobre el tema; Julio Trujillo mira con preocupación, por ejemplo, la incorporación de los creadores al Estado "como último eslabón del funcionariado" (249). Desde la perspectiva de las editoriales independientes, también hay una mirada de preocupación; Adriano Rémura, por ejemplo, considera que las opciones generadas dentro de una cultura estatal tienden a ser uniformes, de manera que "se piensa que porque hay muchas publicaciones (que aun así son pocas), hay muchas opciones, y no es así. Lo que hay es una tendencia a hacer la misma revista. Nos encontramos con fórmulas preescritas de lo que se supone es una revista" (99). Respecto a la proliferación de antologías, Jorge Fernández Granados ha escrito algunas páginas sobre el "laboratorio clónico" y el "canon como mercadotecnia", donde expone el divorcio que ha sufrido la demanda de antologías por interés comercial e institucional y un canon de verdad trascendente en el tiempo (2008). 
su capital simbólico, el matiz negativo por los juicios de valor se reduce: la poesía mexicana más reciente se escribe en el marco de una organización burocrática (estructura organizativa impersonal regulada de manera explícita por medio de la división jerarquizada de funciones especializadas). Si no estudiamos cómo se comportan los productos apoyados por el Estado y la iniciativa privada, al final nos quedaremos en la superficialidad de los juicios apresurados o los simples pre-juicios.

El poeta becario no es la única figura que impacta a esta generación; hay otra menos visible, pero que sin duda resulta también relevante para un campo como la poesía, de escaso interés comercial. En los espacios alternativos que no participan de la normativa burocrática, se crean figuras como la del poeta editor, según ha sucedido con Adriana Tafoya (1976) y Andrés Cisneros de la Cruz (1979), junto a Adriano Rémura al frente de VersodestierrO, o con Mónica Gameros (1971) e Israel Miranda (1974) en Start/Pro. Vivir y escribir al margen del respaldo institucional impulsa las capacidades de creación desde la obra hasta su soporte material, el libro, con lo que el poeta metido a editor encuentra en la autogestión la oportunidad para proponer dinámicas de publicación expeditas (fuera del marco de la burocracia) y más creativas: libros-objeto, la venta de mano en mano, la posibilidad de autopromoción en ferias, dinámicas de presentación y venta como lecturas en cafeterías, etc. En el fondo, sin embargo, el poeta editor no vive de su trabajo poético, sino de su trabajo como editor y como promotor cultural (lo que equivale, al menos en parte, a la profesionalización dentro del aparato estatal... el poeta editor es también un editor y promotor cultural profesional). VersodestierrO y Start/Pro son muy buenos ejemplos de la intensa actividad que puede desplegar un colectivo; otro es el proyecto de Poesía y Combate de Antonio Calera (reseñado por Julián Herbert 2010: 124-133), realizado desde Casa Vecina y sostenido con fondos de la Fundación del Centro Histórico de la Ciudad de México A.C. ${ }^{5} \mathrm{El}$ rechazo a formar filas con la burocracia cultural rara vez viene acompañado por divergencias ideológicas de peso; la verdad es que las editoriales independientes de poesía no conquistan su libertad para

5 Cuyo Comité Ejecutivo fundador estuvo compuesto en 2001 por Carlos Slim, Guillermo Tovar y de Teresa, el cardenal Norberto Rivera Carrera, Jacobo Zabludovsky y tres representantes del Ejecutivo Federal y tres del Gobierno del Distrito Federal. 
criticar al estado ni mucho menos. Sus propósitos son más prácticos: si eluden el apoyo institucional evitan intermediarios y trámites (informes a secretarías, subsecretarías y sub-subsecretarías) y mantienen el control creativo de principio a fin de la obra. Dentro del movimiento de editoriales independientes, donde se percibe que "el poeta político vive de lo que gana como político y no como poeta" y que "los únicos poetas que pueden comer de su obra son los poetas muertos" (Rémura: 102), no se busca una crítica al sistema (en parte, porque el alcance de la poesía es limitado); se intenta, más bien, "generar medios alternos de difusión como sitios para la promoción y la venta, donde participen activamente los integrantes del proyecto editorial y puedan exponerlo a los posibles lectores, puesto que a falta de conocimiento de qué son estas publicaciones se quedan empolvadas en las librerías" (102). En el fondo, la participación del poeta como editor genera una plataforma de comunicación directa con el público, en un complejo proceso de promoción cultural (y autopromoción en muchos casos) que, sin duda, debe producir particularidades visibles en los propios textos. En todo caso, no son mundos excluyentes. ${ }^{6}$

Las condiciones en las cuales se publica y difunde una obra literaria pueden parecer accesorias cuando las pensamos como procesos aislados, pero no desde una perspectiva global: la extensa novela de folletín hubiera sido impensable sin el apoyo para su producción, venta y divulgación, de la imprenta periódica por medio de ese ingenioso sistema que fue la venta por entregas; su redacción hubiera sido impensable si a los escritores de folletín no se les hubiera pagado por volumen escrito y la complejidad de sus nudos narrativos no hubiera sido necesaria de

${ }^{6}$ Nombres como los de Juan Villoro, José María Espinasa, Carmen Boullosa, Antonio Deltoro, Roberto Bolaño, Verónica Volkov, Alfonso D’Aquino, José Luis Rivas y otros, estuvieron asociados por sus primeros libros a editoriales independientes como La Máquina de Escribir (formada con los ahorros de Federico Campbell para un viaje a la India que ya no se realizó) y el Taller Martín Pescador (alrededor de una imprenta antigua con tipos de plomo comprada de oportunidad por Juan Pascoe) (un buen panorama en el trabajo de Carmen Boullosa), pero muy pronto accedieron a imprentas comerciales privadas, estatales y universitarias; casi todos fueron miembros del Sistema Nacional de Creadores de Arte desde sus primeras convocatorias, en 1993-1994 (como puede verse en la página del FONCA, en el apartado correspondiente a Resultados de convocatorias <http://foncaenlinea.conaculta.gob.mx/resultados/resultados.php>) y algunos de ellos han sido pilares para la operación de la Fundación para las Letras Mexicanas o de los sistemas de arbitraje de Conaculta a través del FONCA. 
haber requerido menos entregas; el realismo como poética estuvo estrechamente ligado al positivismo del siglo XIX, pero si las descripciones resultan demoradas fue para cumplir con la extensión de las entregas; el uso abundante de diálogos parece un rasgo estilístico, pero su uso (y abuso) se entiende mejor cuando consideramos que estas novelas se dictaban en su gran mayoría a un secretario para poder cumplir con la celeridad que requería la entrega para la prensa periódica, de modo que la intervención oral se explica mejor por el autor que dicta su creación (y porque la disposición gráfica de los diálogos ayudaba a ocupar espacio más rápido para completar la entrega). Es en este sentido que estudiar y comprender el sistema de producción de esta nueva poesía puede resultar útil para volver sobre sus rasgos caracterizadores.

\section{EsCRIBIR Y DESTACAR (PROMOCIÓN I975-I985): \\ LA IDENTIDAD POR LAS DIFERENCIAS}

¿Cómo escribir dentro de un mercado de tantos competidores para un país de escasos lectores? En México, ni siquiera los estudiantes de la universidad consumen libros y hay más papelerías que librerías (Zaid 2013: 143-154 y 172-189), probablemente a causa de un sistema educativo lleno de deficiencias (Guerrero: 93); en una visión muy pesimista, Josu Landa se refiere a "La poesía en el planeta de los nimios", aquellos lectores cuya formación intelectual paupérrima no les permite apreciar la poesía (109). Si una iniciativa como VersodestierrO resulta eficiente es porque viene acompañada por un sólido proyecto de divulgación (Rémura: 102-105). Un país en el que la queja recurrente es que ni siquiera los mismos poetas se leen entre sí (también Zaid 1980: 12 y Malva Flores: 81-82), ¿cómo distinguirse en el grueso caudal de una grafomanía democratizante surgida en las promociones previas? Esta generación ha respondido a estas demandas de diferentes maneras, aunque todos sus miembros coinciden en un punto: contra la saturación informativa o infoxicación del panorama poético, los miembros de esta generación, ante la competencia, proponen rasgos formales y temáticos que los identifiquen desde la subjetividad, pero borran la anécdota personal para no caer en el subjetivismo ingenuo. Al contrario, una concepción compartida de la poesía como una forma de conocimiento los obliga a una intensa búsqueda de formas y temas distintivos que les 
permitan sobresalir. No es casualidad que falten rasgos caracterizadores para la generación; por ello, cuando Maricela Guerrero (nacida en 1977) intenta definir a la suya, parte de un contexto social compartido y no de rasgos temáticos, formales o estéticos. Si en lo externo de las obras predomina la diferencia, en el fondo creo que toda esta producción converge en la fórmula conciliadora de Jorge Fernández Granados entre poesía pura y poesía social: "si aceptamos que la poesía puede ser una forma de conocimiento - y yo creo que lo es—, ese conocimiento parte necesariamente de la experiencia individual, y podría quedarse sólo allí si no alcanza a ser precisamente poesía, o sea, forma que comunica con palabras una experiencia subjetiva" (2005: 29).

Si buscamos la "similitud de lo disimilar" (Samuel Gordon) para esta generación, creo que podríamos encontrarlo en el uso de diferentes técnicas de enmascaramiento de la experiencia subjetiva y anecdótica. Todos parten de su experiencia personal, pero logran superar el biografismo ingenuo por medio de recursos formales y temáticos variados. Quienes recurren a la tradición literaria, por ejemplo, lo hacen a partir de una lectura personal de su propio canon, acorde a su sensibilidad particular y con sus diferentes estrategias de lectura. En El órgano de la risa (2008), Heriberto Yépez (1974) presenta una propuesta que se origina en la tradición occidental literaria y filosófica (Homero, Kant, Cervantes, el ápeiron, la mónada, etc.) igual que en la mexicana antigua (la ceiba, el diábolo, el venado) y moderna (Durango, Salina Cruz, la televisión, las maquilas), pero cuyo destino principal consiste en fundar una identidad del mestizaje, de lo disimilar, por lo que puede afirmar: "YO NO SOY EL LUGAR / donde ocurre mi identidad. Alguien hizo por mí / Estos trebejos / Yo sólo soy / el lugar donde suceden / las contradicciones" (55) y por lo que "El órgano de la risa desestructura" (17) y es "su pericia, el desacomodo" (15); en el fondo, no abandona el sesgo personalísimo, en conexión con su ensayística ("Canto del transmaíz", por ejemplo, adelanta inquietudes que veremos en La increible hazaña de ser mexicano de 2010). En Los animales invisibles (2012), Luis Jorge Boone juega con el sampleo, la apropiación y la reinterpretación, pero las deudas no inundan las páginas del libro, sino que se dejan al final como una suerte de epílogo que obliga a leer de nuevo un material caracterizado precisamente por su originalidad expresiva (en la que, para ser sinceros, cuesta mucho trabajo advertir la presencia de otros autores); todo lo que era fresco y espontáneo, parece venir del 
reciclaje; en el fondo, propone una estética cifrada en una poética de la lectura individual que continúa, en cierto sentido, el proyecto de Novela (2008): "Leyendo así, como si se escribiera, / todo puede terminar dentro / del poema” (2012: 58). Hernán Bravo Varela (1979), en Oficio de ciega pertinencia (1999) y en Comunión (2002) recupera una tradición literaria muy vasta con mesura, sin caer fácilmente en la pirueta verbal y atraído por imágenes esencialistas, con lecturas personales también, pero con el objetivo de conformar un imaginario poético sólido sobre el que se despliega su imaginación creadora. Ignacio Ruiz Pérez recurre a varios subterfugios literarios en Navegaciones (2006) para llegar a distintas epifanías personales: la máscara literaria (Blake, Coleridge, Pavese, Eliot, etc.) o la máscara recreada (el ciego anónimo de "La señal del cuervo" o el "Divagante" de "Navegaciones", en algo recuerdo de "Simbad el varado" de Owen). Alí Calderón (1982) propone, en Imago prima, una actualización del epigrama de Catulo, con una musa en jeans ajustados a la cadera, un epigrama en verso libre y un estilo dominado por la mezcla desenfadada del estilo coloquial ("me carga la chingada", "mala puta hora", etc.) y una cuidadosa selección del registro culto que ya solo se encuentra en la página impresa (con catervas, protervos, ácimos); esta lectura personal se afina y se despliega en la tesis doctoral que presentó Calderón en 2012, El epigrama en la tradición lírica de México. Manuel Iris (1983) en Cuaderno de los sueños (2009) parte de Catulo y de una asamblea amorosa de buenos lectores de Catulo a la que fueron convocados Bonifaz Nuño, Alí Chumacero y muchos otros, pero con resultados muy distintos, donde la ingeniosa puesta en abismo permite dotar al conjunto de una sinceridad afectiva que no se pierde en la búsqueda de efectos estilísticos.

En otros casos, como en El baile de las condiciones (2011) de Óscar de Pablo (1979), predomina el referente histórico como una base para desarrollar tramas narrativas muy complejas, donde puede mezclarse poesía y reflexión social; en "Nadie (que yo conozca) es Tolomeo III", aprovecha la imagen de un faraón egipcio del siglo III a. C., reconocido benefactor de la cultura de su tiempo, para hablar veladamente de las complejas relaciones entre la creación artística y el estado, eje temático que, pese a su escaso tratamiento, me parece un caracterizador importante de su generación. También atento a la historia cercana, Saúl Ordónez (1981) reconstruye por medio de la máscara poética al asesino serial en Jeffrey (obra negra) (2011), como un pretexto para hablar de 
las relaciones de poder en la pareja, donde se es víctima o victimario, con una vocación decididamente introspectiva. En el caso de Tiempo de Guernica (2005), Iván Cruz Osorio dispone un intenso diálogo desde la historia inmediata, sobre la representación de la violencia cotidiana en los medios de comunicación y sus diversas posibilidades estéticas (aunque el poemario deriva muy pronto hacia el tema de la identidad desde la perspectiva individuo-sociedad, con poemas como "Identidad nacional": "Lo de menos es salir del anonimato. / Pero, sinceramente, no tenemos cara para hacerlo").

Fuera de los referentes literarios, filosóficos, históricos o massmediáticos, la tipología también es amplia. En Nada se pierde (2012), Eva Castañeda (1985) recurre a la hiperestesia para construir una experiencia subjetiva de la vida en una ciudad llena de disonancia y fragmentación, donde las relaciones afectivas se viven aprisa, donde la pérdida de la privacidad en una cultura del hacinamiento urbano genera angustia; contra la imagen de la ciudad como un espacio "moderno", nos presenta una experiencia de frustración constante. Claudina Domingo (1982) nos muestra instantáneas de la ciudad desde la perspectiva subjetiva de una flâneuse en Tránsito (2011); si ambos poemarios coinciden con la generación del desencanto en la relevancia de la ciudad como espacio de autoexploración, se distinguen por su enunciación; en Nada se pierde, la concisión formal apunta más al efectismo de los detalles que a la misma anécdota; en el caso de Tránsito, el estilo dilatado (en el sentido de, por ejemplo, Incurable de David Huerta) se presta más para contar anécdotas de tremendismo adolescente. En Enroque de flanco indistinto (2006), Adriana Tafoya (1974) presenta su experiencia del mundo (el paso del tiempo, la reflexión sobre la identidad del yo, las relaciones humanas) por medio del correlato objetivo del ajedrez, combinación privilegiada de estrategia, toma de decisiones, juego y azar, con lo que las reglas de un juego privilegiadamente racional se convierten en reglas de vida personal; con cierto paralelismo, en Tesauro (2010), Karen Villeda recurre al correlato objetivo (y discursivo, en este caso) del compilado lexicográfico para presentar una visión crítica de los roles femeninomasculino al interior de las relaciones de pareja, en un ingenioso juego donde se va del estereotipo (el rol social, la palabra definida por el diccionario) a su realización personal.

La memoria íntima, como sería de esperar en esta poesía de la inmediatez testimonial, tiene un fuerte protagonismo: Paula Abramo (1980) 
aprovecha su épica personal para llegar a Fiat lux (2012); Zazil Alaíde Collins (1984) recrea su memoria familiar y la sobrepone a la geografía física en No todas las islas (2012). El uso de la memoria, sin embargo, tiene muchas variantes: Camila Krauss (1976) recrea en La consagración de la primavera (2003) y en El ábaco de los acentos (2008) diferentes epifanías de los círculos de relaciones más cercanos de la voz lírica (la vida familiar y las relaciones de pareja), bajo máscaras que van de la estética de la cultura pop a la de la biología y con textos que se unen azarosamente entre sí como en una especie de libro de cabecera; Mónica Gameros (1971), en Kronos (2006), reconstruye las distintas etapas de una relación amorosa, desde la felicidad de los primeros encuentros hasta el desengaño de la separación, por medio de una estética de contrastes (de la imagen poética a la cultura pop) y en un estilo dilatado que juega con los paralelismos, estribillos y otras formas de amplificación que dilatan y al mismo tiempo dan coherencia al texto; Xitlalitl Rodríguez Mendoza (1982) recrea una saga familiar a través de los ojos de un personaje imaginario mitad niño y mitad planta en Datsun (2009) y Karen Villeda (1985) apuesta por la fantasía medieval con un rey, una dama y varios viejos asentados en Babia, una región a la que se le atribuía un efecto tranquilizante, de suerte que la frase "estar en Babia" se proverbializó para referirse a alguien que estaba ensimismado y ausente; Babia (2011), en el fondo, atestigua un universo sobrecogedor de memorias infantiles donde el rey de Babia vive dolorosamente su mutismo.

En todos los casos, podemos ver una serie de experiencias personales presentadas tras el maquillaje de la experiencia compartida (o compartible), en una ecuación donde lo que se subraya es la diferencia entre las propuestas (el color del maquillaje, si se me permite la expresión). La relevancia del individuo no conduce a la exploración ontológica, como sucede con la generación del desencanto (Flores: 91-93) o con la generación de los cincuenta (Calderón 2005b: 56-57), sino a una exploración íntima cuyos resultados procuran ser una sublimación artística de la experiencia personal. De este modo, mientras unos escriben sobre lo que leen y lo subliman en la máscara poética, otros prefieren escribir sobre lo que han vivido y atesoran en la memoria, recreándolo bajo distintas formas literarias, o sobre lo que viven diariamente y es susceptible de ser analizado con una perspectiva crítica, pero siempre con el afán de destacar en el embotellamiento poético de su generación, donde las fórmulas de identidad se multiplican e incluso resulta difícil 
encontrar rasgos compartidos entre un libro y el siguiente escrito por el mismo autor. Pienso, por ejemplo, en proyectos continuos, pero tan diferentes en su realización, como Junkie de nada (2009) y No todas las islas (2012) de Zazil Alaíde Collins o Tesauro (2010) y Babia (2011) de Karen Villeda, donde la clave de la evolución escritural de cada proyecto parece centrada en deslindarse de sus propios libros anteriores.

\section{Hacia una SOCiOlogía del INDIVIDUALISMO POÉTICO \\ Y LA POESÍA DE RUPTURA: UNA POÉTICA DE LA COPRESENCIA}

Hablamos de una generación que no forma filias ni por su estética ni por sus puntos de vista; de una generación cuyos miembros no han tenido el tiempo para estrechar lazos entre ellos, aunque coinciden continuamente en lecturas, presentaciones, páginas web, concursos, editoriales, etc. Como la generación precedente (Gordon: 138), no han firmado un manifiesto conjunto y su incidencia en la cultura ha sido en el plano personal. Pese a no compartir una agenda común ni cultivar un decálogo estético, pareciera que la insignificancia de los componentes sociales, políticos, económicos, culturales, artísticos, etc., de su contexto, los ha conducido naturalmente en una misma dirección. Estamos delante de una generación sometida más a la pérdida de certezas que a orientaciones claras y para la que se radicaliza la distancia cronológica del 68, que ya resulta crítica para Jorge Humberto Chávez (nacido en 1959): "si naciste en el 59 para el 68 tenías nueve años / una edad así puede ser conveniente / por ejemplo para no saber” (38). Si los miembros más prominentes de la generación comparten el individualismo y aspiran a una producción exclusiva que se distinga del resto, esta "similitud de lo disimilar" a la que se refiere Samuel Gordon, quizá no se produce por azar: una mirada a la cronología de Malva Flores en un libro lúcido y redondo como El ocaso de los poetas intelectuales y la "generación del desencanto", nos permite advertir que donde la "literatura difícil" (encabezada por la poesía) revelaba un público especializado, la literatura light o democrática apuntaba a un periodo de democratización de los medios de expresión que sería impensable, por supuesto, sin cuestionar la hegemonía centralista de los años previos (22-25). En ese proceso, saldría a la luz una generación cuya obra podría haberse identificado por su compromiso social como una reacción a la represión política del 68 , 
pero que ante el cambio de los vientos políticos y frente a la tolerancia del gobierno de Echeverría, dejó de tener sentido y cayó en un absurdo expresivo, pasó por el escepticismo al tratarse de una poesía que "no servía para nada" y encalló en una poesía testimonial, hasta convertirse en la generación del desencanto (91-195). Los herederos de una generación desencantada llegan (vivencial, no editorialmente) en este punto.

Quienes nacieron entre 1975 y 1985 están muy alejados del compromiso social; no dependen de circunstancias externas ni de señas de identidad construidas en el trajín político, social, económico o cultural de su contexto, dudoso y decepcionante por la constante desconfianza en las instituciones (al final, han nacido en un mundo de becas que incentivan la creación poética, lo que de alguna manera los ha obligado a "confiar" en las instituciones). Del ejemplo de poetas tan influyentes en la vida pública como Octavio Paz habrán aprendido a separar creación poética y pensamiento político (Pozas Horcasitas: 235-244). Una generación que no vivió la Revolución mexicana y a la que el Movimiento del 68 le llega de oídas. Nacidos durante el sexenio de López Portillo, cruzaron por el sexenio continuista y algo gris de Miguel de la Madrid y vivieron el auge del neoliberalismo mexicano con Salinas de Gortari (y su desplome en términos económicos al final del sexenio), de modo que más que un gobierno autoritario, conocieron una presidencia-gerencia con un rostro democrático (Roderic Ai Camp) y profundamente modernizador (Pozas Horcasitas: 253-265). Son jóvenes que votaron por primera vez en las elecciones del 2000 y ganaron en elecciones democráticas con el Gobierno del Cambio encabezado por Vicente Fox... aunque luego sufrieron durante 6 ańos los escándalos televisivos montados en su contra con el propósito de dar una imagen torpe y ridícula del mismo presidente y de su gabinete (Yépez 2010: 46-59). Fueron protagonistas del Gobierno del Cambio, pero no podían enorgullecerse de ello y en las elecciones del 2012 descubrieron que la alternancia política era una utopía. \#YoSoy132 llegó tarde para ellos y se esfumó rápidamente. $\mathrm{Ni}$ el 68, ni las elecciones del $2000 \mathrm{ni}$ las del 2012 resultaron movimientos suficientemente significativos en sus vidas como para definir su identidad creadora. El fenómeno no es exclusivo de México, como lo demuestra su repetición en otras latitudes; Ben Clark (Ibiza, 1984) se queja en uno de los poemas de Los hijos de los hijos de la ira (2006) de que sus padres les reprocharon no conocer el hambre de la guerra ni el ruido de las bombas al caer, pero a su 
generación le tocó perder el pasto en el parque a cambio de la plancha fría de hormigón ("'Hijos de la bonanza' nos llamaban [...] Y cuando nuestras piernas tan delgadas / caían y sangraban porque el parque / era de un hormigón armado y frío, / se quedaban callados, observando I nuestro llanto con un gesto de sorna": 15); Nurit Kasztelan (Buenos Aires, 1982), en la Lógica de los accidentes, mira a las generaciones de la dictadura argentina con la misma distancia crítica en el poema "Del aire no se tiene memoria pero de la falta sî" ("Todavía me resuena / una frase de mi abuelo / con ese complejo de guerra: / comete todo el plato / la comida no se tira. // El miedo siempre / que en el futuro falte").

Quizá algo que podría unirlos en un futuro sea una preocupación generalizada por la violencia, aunque los productos artísticos sobre el tema proceden de generaciones anteriores (por ejemplo, Te diría que fuéramos al río Bravo a llorar pero debes saber que ya no hay río ni llanto [2013] de Jorge Humberto Chávez) o están localizados geográficamente (como Puño de whisky de Edgar Rincón Luna en 2005); algunos de los autores han renunciado en parte a la poesía y afrontan temas como el feminicidio y la violencia en general en la novela, como ha hecho César Silva Márquez en Los cuervos y Una isla sin mar (244-246). Fuera de estas coordenadas geográficas, por desgracia, la violencia actual (con desarrollos particulares como el "narco") no deja de ser parte de un imaginario cultural que se origina en las películas de rumberas de Juan Orol (o, al menos, así lo perciben muchos; véase Maricela Guerrero: 86 y 90) o en la cultura del amarillismo televisivo, como sucede en Tiempo de Guernica de Iván Cruz Osorio.

Vemos a una generación que no participó en movimientos sociales porque creció con una idea muy reducida del ejercicio de la ciudadanía y que no podía identificarse con el movimiento del EZLN porque ni la escuela ni su visión de mundo los había preparado para ello (¿Chiapas? ¿Dónde estaba Chiapas en el imaginario cultural nacional en 1994? ¿Dónde estaba y está hoy en los libros de texto gratuitos de la SEP?); que no podía identificarse con los feminicidios de Ciudad Juárez desde su corta perspectiva de nación, porque Ciudad Juárez encarnaba un territorio ajeno respecto a lo que había aprendido. La educación pública y privada se había encargado de reducir el tema de la formación ciudadana a su mínima y más inútil expresión; para quienes nacieron más temprano, durante el sexenio de Miguel de la Madrid (1982-1988), sobre la participación cívica encontraron "que el estribillo es 'la libertad 
de expresión' que gozamos en México" y poco más (Corona y de la Peza: 26); durante el sexenio de Carlos Salinas (1988-1994), presenciaron una reforma atropellada que desembocó en una idea de ciudadanía pasiva y en una retórica de la identidad nacional uniforme e intemporal que dejaba fuera de la jugada nacional a Chiapas o a Ciudad Juárez. Como apuntan Sarah Corona y Carmen de la Peza para el periodo 1988-1994:

El libro de la sep de Historia $\sigma^{\circ}$ grado que circula con tirajes millonarios, oculta el carácter político de la nación, no permite entender la nación como un pacto entre hombres diferentes entre sí, que deciden convivir en el espacio público, y acordar por el discurso y la acción concertada las formas de convivencia. [...] El eje cívico que atraviesa este texto, no es la educación de la ciudadanía, sino una condición innata que se expresa en los rituales (las fiestas patrias) y los mitos (los héroes y sus hazañas) en torno a los cuales se ha construido la memoria colectiva y la "identidad" nacional. La historia de México se plantea como un proceso, una línea de continuidad, en la cual los "buenos mexicanos" han ido preservando los "principios" como "herencia" en los cuales se funda y encuentra legitimidad la identidad nacional.

A manera de anexo el texto de Historia $6^{\circ}$ grado incluye un apartado de actividades para cada una de las lecciones. Los ejercicios propuestos están orientados a desarrollar habilidades: de lectura y comprensión de textos, para ordenar, clasificar y relacionar información: "anota cada hecho en el lugar que le corresponde", y de memorización "¿Por cuáles estados de la República pasaban los ferrocarriles?". Ninguna actividad está relacionada con el desarrollo de habilidades de juicio crítico o aquellas orientadas a la aplicación de conocimientos a situaciones nuevas. La característica general de las actividades incluidas enseñan al niño el "saber que" pero no el "saber cómo". Al niño como futuro ciudadano se le enseña a conservar pasivamente la herencia de sus antepasados y amar a la patria, para lo cual solo tiene que conocer sus héroes y rituales (28).

Los programas educativos no enseñaban en esos años (ni tampoco en los previos ni en los siguientes) a vivir en sociedad ni a distinguir en las diferencias locales, causas comunes. Con el paso del tiempo, todos estos poetas llegarían a una universidad, pública o privada, en un ambiente poco estimulante por su burocratización, por su pobreza cultural originada en una enseñanza previa básica y media y cierta inapetencia 
en los círculos académicos (Zaid 2013: 70-72). Para muchos, la universidad sería un trámite penoso, pero necesario.

El panorama político tampoco resultó alentador para generar temas comunes. No es un problema de represión ni nada parecido; se trata, simple y llanamente, de una cadena de situaciones que han sido ridículas o ridiculizadas por los medios de comunicación; desde los videoescándalos del "Niño verde" o el "Góber precioso" hasta los deslices de Fox o López Obrador, la política en México está llena de veleidades que caben bien en un programa de televisión abierta en cadena nacional, pero que, desde una perspectiva literaria, tendrían lugar "acaso, en un poema satírico" (Trujillo: 257). El terreno político difícilmente puede generar una literatura seria, invadido por funcionarios que no debaten ideas con argumentos, sino con descalificaciones mutuas; de personalidades televisivas encumbradas o rebajadas de acuerdo a los intereses del momento; de personajes caricaturizados (incluso por sí mismos); de figuras públicas en las que cada vez que se expone su perfil privado sale a relucir la prepotencia y el abuso. La narrativa que se desprende de estos referentes no puede apartarse mucho de la sátira común, al estilo de $\mathrm{Na}$ ción TV, la novela de Televisa (2013), de Fabrizio Mejía Madrid. Resulta imposible encontrar en el ámbito político un referente que no caiga en estos tópicos (al fin y al cabo, describir a esta clase nos llevaría de vuelta a "El presidente", publicado ya por Jorge Hernández Campos en 1954).

Ante la falta de un ambiente estimulante para la producción de un pensamiento crítico y una conciencia social, Pablo Molinet (1975) escribe: "Quizá nuestra época nos dejó hablando solos" (93). No es de extrañar: luego de 1968, las concentraciones de jóvenes fueron vistas como un peligro y se dispuso de planes muy ambiciosos para generar dinámicas relacionales entre ellos que estorbaran la formación de movimientos sociales. Hoy vemos cumplidos estos planes con los nacidos entre 1975-1985: cuando los nombres de estos escritores coinciden en una revista, siempre es dentro de un marco institucional y académico. ${ }^{7}$ Cuando coinciden en un concurso literario o en los procesos de solicitud de becas de creación, difícilmente pueden pensar en una dinámica

\footnotetext{
${ }^{7}$ Pliego 16 o Revista Fundación funcionan como voceras de la Fundación para las Letras Mexicanas; Punto de Partida o Periódico de Poesía, de la Universidad Nacional Autónoma de México; Círculo de Poesía está vinculada al Cuerpo Académico "Literatura y Cultura Mexicana: Tradición y Ruptura” de la Benemérita Universidad Autónoma de Puebla, universidad a la que pertenecen varios de los miembros de su consejo editorial.
} 
relacional diferente a la competencia entre ellos (el enemigo no es el sistema político que los convoca, sino cada uno de los aspirantes). Cuando van juntos a una lectura, responden en realidad a una convocatoria y a la necesidad de nutrir un currículum profesional; cuando escuchan a sus compañeros, ejercen de jueces para no repetir la fórmula en una angustia continua de las influencias no con los padres (en la conocida fórmula de Harold Bloom), sino con sus contemporáneos; incluso en las páginas más democráticas se pasa por un proceso de selección y rating. ${ }^{8}$ No hay causas comunes y no puede haberlas cuando el reconocimiento poético depende de la competencia constante (por becas, por premios, por puntos en el currículum).

La inyección de fondos públicos se transformó a corto plazo en la "grafomanía" de una clase media (Cohen: 219-220 y Flores: 58-59) y, a mediano plazo, en "la grafomanía de nuestra analfabeta sociedad" (Herbert 2010: 18), lo que para los verdaderos poetas, en un cauce de profesionalización, solo significa más tráfico y una competencia mayor en el de por sí ya concurrido mundo de la poesía. El embotellamiento poético no trae consigo, por supuesto, una nómina más amplia de lectores y aquí vuelve a resultar pertinente el "Quizá nuestra época nos dejó hablando solos” (Molinet: 93). Hoy, la poesía no aparece en los titulares de los periódicos e, incluso en publicaciones especializadas sobre poesía centradas en la nota o la reflexión, cuesta trabajo encontrar poemas (Krauss 2010) y al periodismo cultural es lo que menos le importa (Zaid 2013: 59-65). En el terreno de la educación, la inversión pública no ha tenido consecuencias directas entre los lectores (Zaid 2013: 59-65 y 86-95), lo que restringe el consumo a los escasos lectores aptos (Guerrero: 92-94): un grupo reducido de poetas jueces (en los concursos literarios), de poetas administradores (en los procesos de selección para becas), de poetas editores (dentro de varias colecciones de poesía), de poetas que desean estar informados sobre lo que escribe la competencia, de poetas aficionados que aspiran a publicar, etc. Esta generación escribe, en suma, para un público especializado; lo que llama Mario Bojórquez "lectores profesionales" (212) y Hernán Bravo

\footnotetext{
${ }^{8}$ Como sucede con "Las afinidades electivas / Las elecciones afectivas, curaduría autogestionada de poesía mexicana reciente" <http://laseleccionesafectivasmexico.blogspot.mx>, donde en cada ficha aparece una lista de poetas que "mencionan" al poeta en cuestión y se presenta una lista de "elegidos".
} 
Varela, "el gusto de sus colegas y especialistas, la protección del aparato cultural” (2010: 53). ¿Esto es malo? No, pero forma un círculo vicioso: al reconocerse como un público restringido y bien identificado por su capacidad lectora, la competencia para distinguirse unos de otros termina en el callejón sin salida de una poesía que fácilmente puede llegar a los extremos expresivos, a menudo incomprensible fuera del grupo de iniciados; cuando los poetas asumen que serán leídos por otros poetas con igual o mayor entrenamiento poético (por ejemplo, en un concurso), resulta fácil también asumir que comparten con este público especializado un lenguaje cifrado por la intertextualidad, las correspondencias, las alusiones ingeniosas, etc., y escribir de acuerdo a ello. El más original tendrá más posibilidades de ganar. Como apunta Jorge Fernández Granados, el poeta pasa de la plaza pública al laboratorio y escribe, en consecuencia, con el lenguaje de los especialistas (2005: 29-31). Escribir para lectores especializados genera un lenguaje especializado que se desentiende del lector común. No se trata, por supuesto, de algo que puede achacarse solo a esta generación: en 1989, Octavio Paz defendía al público de la poesía que resultaba escaso, pero leía mucho mejor; ecos de esto pueden escucharse hasta en Josu Landa (2010: 111-112). Este paradigma de lectura, algo narcisista, debería revisarse desde la perspectiva de las estrategias de composición que produce (por ejemplo, Higashi en prensa) y no solo como una queja o un indicio saludable según el lado de donde se vea.

Se trata de una generación que creció a la sombra de un "experimento" como Poesía en movimiento, publicado por primera vez en 1966, pero que en 1990 había alcanzado la 21 a edición en Siglo XXI, antología que apostaba por la poesía de ruptura y el poema como signo (Escalante 2013: 91-94). En cierto sentido, la poesía de la generación de 1975-1985 radicaliza los efectos de esta postura estética y generacional, en su énfasis para distinguir entre una generación y otra. Si en 1966, en una antología preparada por poetas de generaciones y posiciones muy diferentes en el campo literario como Alí Chumacero, Homero Aridjis, José Emilio Pacheco y Octavio Paz, se proponía que para entender una poesía en movimiento resultaba necesario fundar una "tradición de la ruptura", esta noción resultaba ya paradójica en una fecha tan temprana como $1980 .{ }^{9}$ Para esta generación, la noción de tradición de ruptu-

9 Escribía Gabriel Zaid que era "insólito" que se reeditara tanto "para el tipo de antología que es: su éxito inmoviliza el movimiento desde 1966” (1980: 12) y Sandro 
ra, ligada estrechamente a la figura de Octavio Paz (Stanton 1998: 51 60; Escalante 2013: 77-94), se agudiza no por un cambio radical en la estética de Octavio Paz (cuya mejor exposición se encuentra en Los hijos del limo [1974] y en La otra voz [1990] [Paz: 321-473 y 489-592]), sino por un cambio en nuestra sensación del paso del tiempo. Si para Paz las rupturas se daban entre generaciones (de ahí su importancia), la copresencia fomentada por una organización más democrática y horizontal ha tenido un efecto catalizador: la ruptura ya no se da en un marco cronológico vertical entre miembros de distintas generaciones, sino que se produce en la copresencia de los programas de creación, de los talleres literarios, de los concursos por becas y por premios. Como señala Julián Herbert con mucho tino, lo que ha cambiado respecto al concepto actual de generación "no es académico ni — exclusivamente- estilístico sino cultural: el de nuestro sentimiento del tiempo" (2010: 21-23). Se trata, desde una perspectiva estética, de una generación donde se pueden apreciar ya las consecuencias de una convivencia regulada bajo las normas de un estado administrador, donde la convivencia organizada ha conducido al deslinde de la propiedad intelectual contigua, identificada por una poética de la ruptura en copresencia generacional.

\section{FINAL}

Ni la nómina de autores de la generación ni la serie de características compartidas entre estos poetas, tan diferentes entre sí, parece ofrecer resultados útiles para hablar de una generación. Como escribe Fernández Granados con agudeza y humor, "anunciar una nueva generación tiene para mí algo de campaña publicitaria. Inventar familias ahí donde solo hay individuos es propio más bien de CONAPO" (2005: 33). Una generación, en la actualidad, no se explica desde su comunión y sus rasgos comunes (que son escasos), sino desde su dispersión conflictiva por una copresencia obligada: los miembros al interior del taller literario, en una licenciatura o posgrado en creación literaria, los concursantes de un premio o una beca, quienes gozan de un financiamiento público vs. los independientes, quienes publican en editoriales estatales vs. quienes

Cohen, en 1987, la definía como "la antología 'oficial' de la poesía mexicana de este siglo" (221). 
no, quienes tienen más currículum contra los que tienen menos, etc. En suma, podemos advertir procesos estéticos que se inician por la percepción de factores externos, durante procesos sociales conflictivos que implican la comparación y el consecuente deslinde de propuestas estéticas. En la poética de un autor no se busca comulgar, sino que se busca el deslindarse, el indefinirse; el producto literario coincide en aspectos formales básicos estatutarios, pero luego se deslinda rápidamente de sus compañeros de generación y de generaciones anteriores con un producto disimilar. Los productos poéticos demuestran, sin embargo, tendencias tenues, pero es claro que no se sostienen en una base estética, donde los autores de la generación han encontrado la manera de allegarse rasgos distintivos, sino en una base común dentro de su formación (la privación de referentes sociales comunes prestigiosos, al estilo del 68, o la radicalización de la experiencia subjetiva como efecto secundario de la búsqueda de una identidad). Se trata, en fin, de categorías muy lejanas al esteticismo intemporal al que estamos acostumbrados, pero categorías concretas al fin que nos pueden ayudar, sumadas a otras plataformas de análisis, a entender el panorama literario de los últimos años desde sus causas sociológicas y hasta sus consecuencias estéticas.

\section{BiBLIOGRAFÍA}

Abramo, Paula. Fiat lux. México: Fondo Editorial Tierra Adentro, 2012.

Bernal Granados, Gabriel. "Editoriales independientes de poesía en los ochenta y los noventa [en México]", Crítica, 151 (octubre-noviembre, 2012): 23-30.

Bojórquez, Mario. "Poesía en la plaza", en Rogelio Guedea y Jair Cortés (comp.). A contraluz, poéticas y reflexiones de la poesía mexicana reciente: 208-215.

Boone, Luis Jorge. Novela. México: Fondo Editorial Tierra Adentro, 2008.

Boone, Luis Jorge. Los animales invisibles. México: Consejo Nacional para la Cultura y las Artes, 2012.

Boullosa, Carmen. "Los editores salvajes", Gatopardo, 81 (julio 2007): 5869.

Bravo Varela, Hernán. Oficio de ciega pertinencia. Guadalajara: Consejo Nacional para la Cultura y las Artes, 1999.

Bravo Varela, Hernán. Comunión. México: Ediciones del Ermitaño, 2002. 
Bravo Varela, Hernán. "Malversaciones", en Julián Herbert, Javier de la Mora y Santiago Matías (comps.). Escribir poesía en México: 39-58.

Calderón, Alí. El epigrama en la tradición lírica de México. Tesis de doctorado. México: Universidad Nacional Autónoma de México, 2012.

Calderón, Alí. Imago prima. México: Universidad Autónoma de Zacatecas, 2005a.

CALDerón, Alí. La generación de los cincuenta. Un acercamiento a su discurso poético. México: Consejo Nacional para la Cultura y las Artes / Secretaría de Cultura del Estado de Puebla / Fondo Editorial Tierra Adentro, 2005b.

Camp, Roderic Ar. The Metamorphosis of Leadership in a Democratic Mexico. New York: Oxford University Press, 2010.

Castañeda, Eva. Nada se pierde. México: VersodestierrO, 2012.

Chávez, Jorge Humberto. La ciudad y el viaje interminable. Antología personal, 1980-2000. San Antonio, Texas: Entrelíneas Editores, 2003.

Clark, Ben. Los hijos de los hijos de la ira. Madrid: Hiperión, 2006.

Cohen, Sandro. "Poesía nueva en México", en Norma Klahn y Jesse Fernández (comps.). Lugar de encuentro, ensayos criticos sobre poesía mexicana actual. México: Katún, 1987: 219-229.

Collins, Zazil Alaíde. No todas las islas. México: Gobierno del Estado de Baja California Sur / Instituto Sudcaliforniano de Cultura / Consejo Nacional para la Cultura y las Artes, 2012.

Collins, Zazil Alaíde. Junkie de nada. México: Lenguaraz, 2009.

Corona, Sarah y Carmen de la Peza. "La educación ciudadana a través de los libros de texto", Sinéctica [en línea], 16 (enero-junio de 2000): 16-30. Artículo en línea disponible en <http://www.redalyc.org/ pdf/998/99815740004.pdf> [Consulta: 27 de agosto de 2013].

Cruz Osorio, Iván. Tiempo de Guernica. México: Praxis, 2005.

Domingo, Claudina. Tránsito. México: Fondo Editorial Tierra Adentro, 2011.

Escalante, Evodio. Las sendas perdidas de Octavio Paz. México: Universidad Autónoma Metropolitana / Ediciones sin Nombre, 2013.

Escalante, Evodio. "La tradición radical en la poesía mexicana, 1952-1984", Casa del Tiempo, $49-50$ (febrero-marzo 1985): 15-31.

Fernández Granados, Jorge. "Islas que comulgan con otras islas", en Rogelio Guedea y Jair Cortés (comps.). A contraluz, poéticas y reflexiones de la poesía mexicana reciente: $24-35$.

Fernández Granados, Jorge, "Panoramas perversos o acerca de la construcción artificial del prestigio", Ciberayllu [en línea], 14 de diciembre del 2008. Artículo en línea disponible en <http://www.ciberayllu.org/ Comentario/JFG_Prestigio.html> [Consulta: 16 de febrero de 2013]. 
Flores, Malva. El ocaso de los poetas intelectuales y la "generación del desencanto”. Xalapa: Universidad Veracruzana, 2010.

Gameros, Mónica. Kronos. México: Start/Pro, 2006.

Gordon, SAmuel. "Breves atisbos metodológicos para el examen de la poesía mexicana al fin de siglo", en Graffylia, 3 (enero- julio 2004): 129-142.

Guedea, Rogelio y Jair Cortés (comps.). A contraluz, poéticas y reflexiones de la poesía mexicana reciente. Selección y prólogo de Rogelio Guedea y Jair Cortés. México: Fondo Editorial Tierra Adentro, 2005.

Guerrero, Maricela. "Los setenta, una generación a caballo", en Julián Herbert, Javier de la Mora y Santiago Matías (comps.), Escribir poesía en México: 83-94.

Herbert, Julián. "Apuntes para una filosofía de la descomposición”, en Rogelio Guedea y Jair Cortés (comps.). A contraluz, poéticas y reflexiones de la poesía mexicana reciente: 192-206.

Herbert, Julián. Caníbal. México: Bonobos, 2010.

Herbert, Julián, Javier de la Mora y Santiago Matías (comps.). Escribir poesía en México. México: Bonobos / Consejo Nacional para la Cultura y las Artes, 2010.

Higashi, Alejandro. "La poesía como intuición. Segunda parte. ¿Quién lee poesía en México? Consumismo, exclusividad y poesía", Ancila, Crítica de Poesía Mexicana Contemporánea [en línea], en prensa.

Iris, Manuel. Cuaderno de los sueños. México: Fondo Editorial Tierra Adentro, 2009.

Jiménez Aguirre, Gustavo. “Tendencias en la poesía emergente de México. Un panorama nuevo cada día”, Tierra Adentro, 100 (octubre-noviembre de 1999): 74-81.

Kasztelan, Nurit. Lógica de los accidentes. Buenos Aires: Vox, 2013.

Krauss, Camila. La consagración de la primavera. Xalapa: Gobierno del Estado de Veracruz, 2003.

Krauss, Camila. El ábaco de los acentos. México: Fundación para las Letras Mexicanas / Ediciones sin Nombre, 2008.

Krauss, Camila. "El Periódico de Poesía de la unam. ¿Es la red a la poesía lo que el periódico fue para la novela en el siglo xIx?”, Replicante, Cultura Critica y Periodismo Digital [en línea], octubre 2010. Artículo en línea disponible en <http://revistareplicante.com/el-periodico-de-poesia-dela-unam/> [Consulta: 30 de julio de 2013].

Landa, Josu. "La poesía en el planeta de los nimios”, en Julián Herbert, Javier de la Mora y Santiago Matías (comps.), Escribir poesía en México: 95-117.

Lumbreras, Ernesto y Hernán Bravo Varela. "Prólogo", en El manantial latente, muestra de poesía mexicana desde el ahora, 1986-2002. México: Consejo Nacional para la Cultura y las Artes, 2002. 
Mata, Rodolfo. "Renovación de la poesía mexicana actual”, Fractal [en línea], 42 (julio-septiembre 2006). Artículo en línea disponible en <http:// www.mxfractal.org/F42Mata.htm> [Consulta: 31 de julio de 2013].

Mata, Roldolfo. "Tensóes e vertentes da poesia mexicana (1996-2004)", Sibila, Revista Semestral de Poesia e Cultura, 6, año 4 (mayo 2004):75-86.

Mateo Gambarte, Eduardo. El concepto de generación literaria. Madrid: Síntesis, 1996.

Mejía Madrid, Fabrizio. Nación TV, la novela de Televisa. México: Grijalbo, 2013.

Miranda Salas, R. Israel. Polaroids. México: Start/Pro, 2006.

Molinet, Pablo. "La lección de la urraca", en Rogelio Guedea y Jair Cortés (comps.). A contraluz, poéticas y reflexiones de la poesía mexicana reciente: 78-98.

OrdóŃEz, SAÚL. Jeffrey (obra negra). México: Fondo Editorial Tierra Adentro, 2011.

Pablo, Óscar de. El baile de las condiciones. México: Consejo Nacional para la Cultura y las Artes, 2011.

Paz, Octavio. La casa de la presencia. Poesía e historia. Edición de Autor. $3^{a}$ reimpr. México: Fondo de Cultura Económica / Círculo de Lectores, 1999 [ed. or. 1991].

Plascencia Nol, León. "Noigandres y el arte de la suplantación (un editor de poesía en México)", en Julián Herbert, Javier de la Mora y Santiago Matías (comps.), Escribir poesía en México: 220-235.

Pozas Horcasitas, Ricardo. "La modernidad de los modernizadores", en Anthony Stanton (ed.), Octavio Paz, entre poética y politica. México: El Colegio de México, 2009: 235-293.

RÉmura, Adriano. "Autonomía o del por qué hacer un proyecto civil", Tirofijo. Revista Cultural del Bajío 00, año 1 (verano 2008): 97-105.

Rincón Luna, Edgar. Puño de whiskey. México: Ediciones sin Nombre, 2005.

Rodríguez Mendoza, Xitlalitl. Datsun. México: Universidad Nacional Autónoma de México, 2009.

Ruiz Pérez, Ignacio. Navegaciones. Tuxtla Gutiérrez: Gobierno del Estado de Chiapas, 2006.

Silva Márquez, César. "Ciudad Juárez y Led Zeppelin son la misma cosa", en Julián Herbert, Javier de la Mora y Santiago Matías (comps.), Escribir poesía en México: 239-246.

Stanton, Anthony. "Octavio Paz como lector crítico de la poesía mexicana moderna", en Nueva Revista de Filología Hispánica, 49, 1 (2001): 53-79.

StANTON, Anthony. Inventores de la tradición: ensayos sobre poesía mexicana moderna. México: El Colegio de México / Fondo de Cultura Económica, 1998. 
Tafoya, Adriana. Enroque de flanco indistinto. México: VersodestierrO / Mezcalero Brothers, 2006.

Trujillo, Julio. "El poder o la gloria, apuntes sobre poesía y política”, en Julián Herbert, Javier de la Mora y Santiago Matías (comps.), Escribir poesía en México: 247-258.

Villeda, Karen. Tesauro. México: Fondo Editorial Tierra Adentro, 2010.

Villeda, Karen. Babia. México: Universidad Nacional Autónoma de México, 2011.

VolPi, Jorge. "Los críticos, los premios y el mercado literario, cinco consideraciones intempestivas", en Renacimiento, 39 (2003): 24-29.

Yépez, Heriberto. Contra la tele-visión. México: Tumbona Ediciones, 2010.

Yépez, Heriberto. El órgano de la risa. México: Consejo Nacional para la Cultura y las Artes / Aldus, 2008.

Zaid, Gabriel. Dinero para la cultura. México: Debate / Mondadori, 2013.

Zaid, Gabriel. Asamblea de poetas jóvenes de México. Presentación de Gabriel Zaid. México: Siglo XXI, 1980.

FECHA DE RECEPCIÓN: 5 de noviembre 2013.

FECHA DE ACEPTACión: 11 de marzo de 2014. 